\title{
Different effects of cardiac and diaphragm function assessed by ultrasound on extubation outcomes in difficult-to-wean patients: a cohort study
}

Ling Luo ${ }^{1,2}$, Yidan Li ${ }^{3}$, Xiukai Chen ${ }^{4}$, Bing Sun ${ }^{1}$, Wenxiong Li ${ }^{4}$, Wei Gu ${ }^{5}$, Shuo Wang ${ }^{5}$, Song Zhao ${ }^{4}$, Yanwei Lv ${ }^{6}$, Mulei Chen ${ }^{7}$, Jingen $\mathrm{Xia}^{8}$, Feng Sui ${ }^{4}$, Xue Mei ${ }^{5}$, Huanzhong Shi ${ }^{1}$ and Zhaohui Tong ${ }^{1 *}$

\begin{abstract}
Background: Ultrasound is a convenient tool to evaluate cardiac and diaphragm function. The ratio (E/Ea) of mitral Doppler inflow velocity to annular tissue Doppler wave velocity by transthoracic echocardiography (TTE) and diaphragmatic excursion (DE) by diaphragm ultrasound have been confirmed in predicting extubation outcomes independently, however their different roles in the weaning process have not been determined until now.

Methods: We designed a cohort study to preform diaphragm ultrasound and TTE before and after the spontaneous breathing trial (SBT) in difficult-to-wean patients. Patients considered for enrollment should succeed on a SBT and have been extubated. They were followed up with the events of respiratory failure within $48 \mathrm{~h}$, and divided into the respiratory failure and extubation success subgroups. Relevant risk factors predicting respiratory failure were analysed by a multivariate logistic regression model. Then, each subgroup was assessed with respect to re-intubation within 1 week, and divided into the re-intubation and non-intubation subgroups. Furthermore, relevant risk factors predicting re-intubation were also analysed in each subgroup. The area under the curve (AUC) and optimum cut-off value were identified by the receiver operating characteristic curve.
\end{abstract}

Results: Among 60 patients, 29 cases developed respiratory failure within 48 h, and 14 cases were re-intubated or died within 1 week, respectively. Multivariate logistic regression analysis showed that E/Ea (average) after SBT [odds ratio (OR) 1.450, 95\% confidence intervals (Cl) 1.092-1.926, $P=0.01$ ] and left ventricular ejection fraction were associated with respiratory failure. The AUC of E/Ea (average) after SBT was 0.789 , and a cut-off value $\geq 12.5$ showed the highest diagnostic accuracy with a sensitivity and specificity of $72.4 \%$ and $77.4 \%$, respectively. Furthermore, in the respiratory failure subgroup only DE (average) after SBT was associated with re-intubation (OR 0.690, Cl 0.499-0.953, $P=0.024$ ). The AUC of DE (average) after SBT was 0.805 , and a cut-off value $\leq 12.6 \mathrm{~mm}$ showed the highest diagnostic accuracy with a sensitivity and specificity of $80 \%$ and $68.4 \%$, respectively.

Conclusions: E/Ea (average) after SBT could help predict respiratory failure within $48 \mathrm{~h}$. However, DE (average) after SBT could help predict re-intubation within 1 week in the respiratory failure subgroup.

Keywords: Weaning, Extubation, Cardiac function, Echocardiography, Diaphragm function

\footnotetext{
* Correspondence: tongzhaohuicy@sina.com

${ }^{1}$ Department of Respiratory and Critical Care Medicine, Beijing Institute of Respiratory Medicine, Beijing Chaoyang Hospital, Capital Medical University, NO. 8 Gongren Tiyuchang Nanlu, Chaoyang District, Beijing 100020, China Full list of author information is available at the end of the article
} 


\section{Background}

Predictors of extubation outcomes are consistently difficult issues for patients with a high risk of difficult weaning. Common reasons for extubation failure include primary respiratory failure, cardiac dysfunction, ineffective cough, excess secretions, upper airway obstruction and other aetiologies $[1,2]$. The ideal indicators would not only predict extubation failure, but would also confirm the reasons for such failures. Traditional indicators, such as respiratory rate (RR), minute ventilation, tidal volume $\left(\mathrm{V}_{\mathrm{T}}\right)$, and the rapid shallow breathing index (RSBI), can reflect patients' integral conditions, but it is difficult to apply them in the analysis of the exact reasons for such failures. Some studies have reported that B-type natriuretic peptide (BNP) or N-terminal-pro-BNP (NT-pro-BNP) could help identify patients who failed to wean due to cardiac dysfunction. Nevertheless, it was difficult to confirm the cut-off values; because they were easily affected by age, renal function, weight, infection, etc. [3-5].

Bedside ultrasound is a convenient tool to evaluate cardiac function, diaphragm function, lung aeration, etc. Cardiac dysfunction is one of the important risk factors for extubation failure. Recent studies have indicated that the ratio $(\mathrm{E} / \mathrm{Ea})$ of mitral Doppler inflow velocity $(\mathrm{E})$ to annular tissue Doppler wave velocity (Ea) by transthoracic echocardiography (TTE) could help identify the cardiac origin of weaning failure [6-9]. In addition to cardiac dysfunction, diaphragm dysfunction is another critical reason for extubation failure. Some studies have reported that diaphragmatic excursion (DE) or liver/spleen movements could predict extubation failure [10-12].

Although TTE and diaphragm ultrasound have been confirmed in independently assessing extubation outcomes, few studies have shown their different roles in the weaning process until now. This observational study was designed to test the ability of cardiac and diaphragm function assessed by bedside ultrasound to predict respiratory failure within $48 \mathrm{~h}$ and re-intubation within 1 week after extubation.

\section{Methods}

\section{Patients}

This study was conducted in Beijing Chaoyang Hospital, which has a total of 58 beds in the 4 intensive care units (ICUs) (RICU, SICU, CCU and EICU), over a 16-month period (November 2012 to February 2014). The study was approved by an Institutional Review Board of Beijing Chaoyang Hospital on Sep 24th, 2012 (No.2012-ke-88). Consent forms were obtained from each patient's immediate family members.

All patients were assessed for readiness to wean by their attending physicians. Once the patients failed the spontaneous breathing trial (SBT) at least once and had been intubated for more than $48 \mathrm{~h}$, they were defined as difficult-to-wean patients [13]. Patients considered for enrollment should succeed on a SBT and have been extubated. The exclusion criteria were as follows: (a) pregnant women; (b) age < 18 years; (c) tracheostomy after the SBT; (d) severe mitral stenosis or prosthetic mitral valve; (e) a history of diaphragmatic palsy, cervical spine injury, or neuromuscular disease; (f) pneumothorax or pneumomediastinum; (g) use of muscle-paralyzing agents within $48 \mathrm{~h}$ before the study; (h) poor echocardiographic windows or difficult windows of diaphragmatic movement; (i) extubation failure definitely caused by upper airway obstruction; and (j) planned prophylactic noninvasive ventilation (NIV) after extubation.

\section{Study design}

All patients were connected to a ventilator with pressure support ventilation [pressure support 10-12 $\mathrm{cmH}_{2} \mathrm{O}$, positive end expiratory pressure $5 \mathrm{cmH}_{2} \mathrm{O}$, and proper fraction of inspired oxygen $\left(\mathrm{FiO}_{2}\right) \leq 40 \%$ ] before the SBT. They fulfilled the SBT through a T-piece over $30 \mathrm{~min}$ in a supine position $\left(30^{\circ}-45^{\circ}\right)$. It took 5 to 15 min to perform TTE and diaphragm ultrasound before and after the SBT. The attending physicians remained blinded to the TTE and diaphragm ultrasound results. All patients should be extubated within $24 \mathrm{~h}$ once the SBT has succeeded. Medications, NIV or reintubation could be performed in accordance with the patients' conditions.

Both TTE and diaphragm ultrasound were performed using a Vivid i (GE Medical Systems Israel Ltd) with a 3.0 $\mathrm{MHz}$ US probe. TTE was done after diaphragm ultrasound. Diaphragmatic movement was measured by specific ultrasound doctors with the US probe placed over one of the lower intercostal spaces in the right anterior axillary line for the right diaphragm and left midaxillary line for the left diaphragm. The liver or spleen was used as a window for each hemidiaphragm. A twodimensional mode was used to find the best approach and to select the exploration line for each hemidiaphragm. With the probe fixed on the chest wall during respiration, the ultrasound beam was directed to the hemidiaphragmatic domes at an angle of $\geq 70^{\circ}$; then, M-mode ultrasonography was used to display the motion of the anatomical structures along the selected line $[11,12,14]$. Unilateral diaphragmatic excursion (DE) equalled half of the sum of the values on the vertical axis of the tracing during the inspiration and expiration period, which were measured from baseline to the point of maximum height. DE (average) was equivalent to half of the sum of DE (right) and DE (left). Measurements were recorded at least six times and averaged for each hemidiaphragm. If the rhythm of respiration was not regular, measurements were needed at least ten times. 
All patients were followed up with the events of respiratory failure within $48 \mathrm{~h}$, and they were divided into respiratory failure and extubation success subgroups, accordingly. Respiratory failure was defined by at least two of the following criteria: arterial $\mathrm{pH}<7.35$ with arterial carbon dioxide tension $\left(\mathrm{PaCO}_{2}\right)>45 \mathrm{mmHg}$ or $>20 \%$ higher than baseline; RR $>30$ breaths/min or $\geq 50 \%$ higher than baseline; arterial oxygen tension $\left(\mathrm{PaO}_{2}\right)<60 \mathrm{mmHg}$ or percutaneous oxygen saturation $\left(\mathrm{SpO}_{2}\right)<90 \%$ at $\mathrm{FiO}_{2} \geq 0.5$; decreased consciousness (e.g., coma, stupor, delirium), agitation, or diaphoresis; and clinical signs suggestive of respiratory muscle fatigue or increased work of breathing, such as retraction of intercostal spaces, use of accessory respiratory muscles, or thoracic-abdominal paradoxical movement [13, 15-17].

Then, each subgroup was assessed with respect to reintubation within 1 week, and divided into re-intubation and non-intubation subgroups. The re-intubation should meet one of the following major criteria (a): respiratory or cardiac arrest, persistent severe hypoxemia (ratio of $\mathrm{PaO}_{2}$ to $\mathrm{FiO}_{2} \leq 130 \mathrm{mmHg}$ ) despite NIV, haemodynamic instability with systolic blood pressure $\leq 85 \mathrm{mmHg}$ despite adequate fluids and vasoactive drugs (dopamine or dobutamine $\geq 5 \mu \mathrm{g} / \mathrm{kg} / \mathrm{min}$ or noradrenaline $\geq 0.05 \mu \mathrm{g} /$ $\mathrm{kg} / \mathrm{min}$ ), and severe cardiac arrhythmia; or (b) at least two of the following minor criteria: clinical signs of severe acute respiratory failure with respiratory rate persistently $>35$ breaths $/ \mathrm{min}$, arterial $\mathrm{pH} \leq 7.20$, worsening of acute respiratory failure under NIV, clinical signs suggestive of severely decreased consciousness (e.g., coma, stupor, and delirium) under NIV, bronchial hypersecretion under NIV, and development of other organ failure [13]. The attending doctor decided whether to re-intubate in the end. The re-intubation subgroup included the patients who were re-intubated or died within 1 week after extubation.

The criteria of readiness to wean and the SBT and NIV as well as, and the detailed methods for measuring $\mathrm{E} / \mathrm{Ea}$ and left ventricular ejection fraction (LVEF) are described in Additional file 1.

Records were taken on the patients' characteristics, including age, sex, body mass index (BMI), Acute Physiology and Chronic Health Evaluation (APACHE) II score at the time of admission to the ICU, comorbidities, duration from onset to the first intubation, duration of the first intubation to extubation, $\mathrm{V}_{\mathrm{T}}$ and RSBI before the SBT, white blood cell count, haemoglobin, albumin, plasma creatinine and Glasgow coma scale (GCS) on the day of extubation. The data for DE, E, E/Ea and LVEF, arterial blood gas analysis, lactic acid and NT-pro-BNP were also collected.

\section{Statistical analysis}

Statistical analysis was performed with SPSS 17.0 (Inc., Chicago, IL, USA). Data were expressed as the means \pm SD or median quartile [first-third]. The Unpaired Student's, Mann-Whitney, and the paired Wilcoxon tests were used to compare quantitative variables. Differences in the measurement data were compared with the one-way analysis of variance. Comparisons of proportions were performed with a Chi-square test or Fisher's exact test. Risk factors predicting respiratory failure within $48 \mathrm{~h}$ or re-intubation within 1 week were selected by the backward-Wald method and analysed with a multivariate logistic regression model. The results were displayed in the last step. Meanwhile, the Hosmer-Lemeshow test was performed to verify the goodness of fit of the model. Then the area under the curve (AUC) and optimum cut-off value were identified by the receiver operating characteristic (ROC) curve. The level of significance was fixed at $P \leq 0.05$.

\section{Results}

Figure 1 shows the flow-chart diagram of the study. Of the 75 patients who were screened, 60 patients (age range from 18 to 90 years -old) were enrolled. The reasons for intubation included severe pneumonia $(n=19)$, chronic obstructive airway disease $(n=10)$, cardiac events $(n=15)$, sepsis $(n=7)$, surgery $(n=8)$ and upper gastrointestinal haemorrhage $(n=1)$. The reasons for exclusion included severe mitral stenosis or prosthetic mitral valve $(n=2)$, poor echocardiography images or ultrasonic windows of diaphragm $(n=5)$, tracheotomy after SBT $(n=2)$, extubation failure caused by upper airway obstruction $(n=2)$ and planned prophylactic NIV $(n=4)$. Of 60 enrolled patients, 29 patients developed respiratory failure within $48 \mathrm{~h}$ after extubation, and 14 patients were re-intubated within 1 week.

\section{Predictors of respiratory failure within $48 \mathrm{~h}$}

Among 60 patients, 29 cases (48\%) developed respiratory failure within $48 \mathrm{~h}$ after extubation (respiratory failure subgroup, RF subgroup), and another 31 cases (52\%) were successfully extubated (extubation success subgroup, ES subgroup). There were significant differences in some clinical characteristics between the RF and ES subgroups (Table 1). Partial differences were also seen in the laboratory and ultrasound data (Table 2). Multivariate logistic regression showed that $\mathrm{E} / \mathrm{Ea}$ (average) after SBT [odds ratio (OR) 1.450, 95\% confidence intervals $(\mathrm{CI}) 1.092-1.926, P=0.01$ ] and the LVEF (OR 0.904, CI 0.833-0.981, $P=0.015$ ) were closely related to respiratory failure within $48 \mathrm{~h}$. The $P$ value for the Hosmer-Lemeshow test was 0.11. The AUC of E/Ea (average) after SBT was 0.789 , and a cut-off value $\geq 12.5$ showed the highest diagnostic accuracy with a sensitivity and specificity of $72.4 \%$ and $77.4 \%$, respectively (Fig. 2). The results of logistic regression and the ROC curve in this study were summarized in Table 3. For example, compared with a case of extubation success (Fig. 3), 


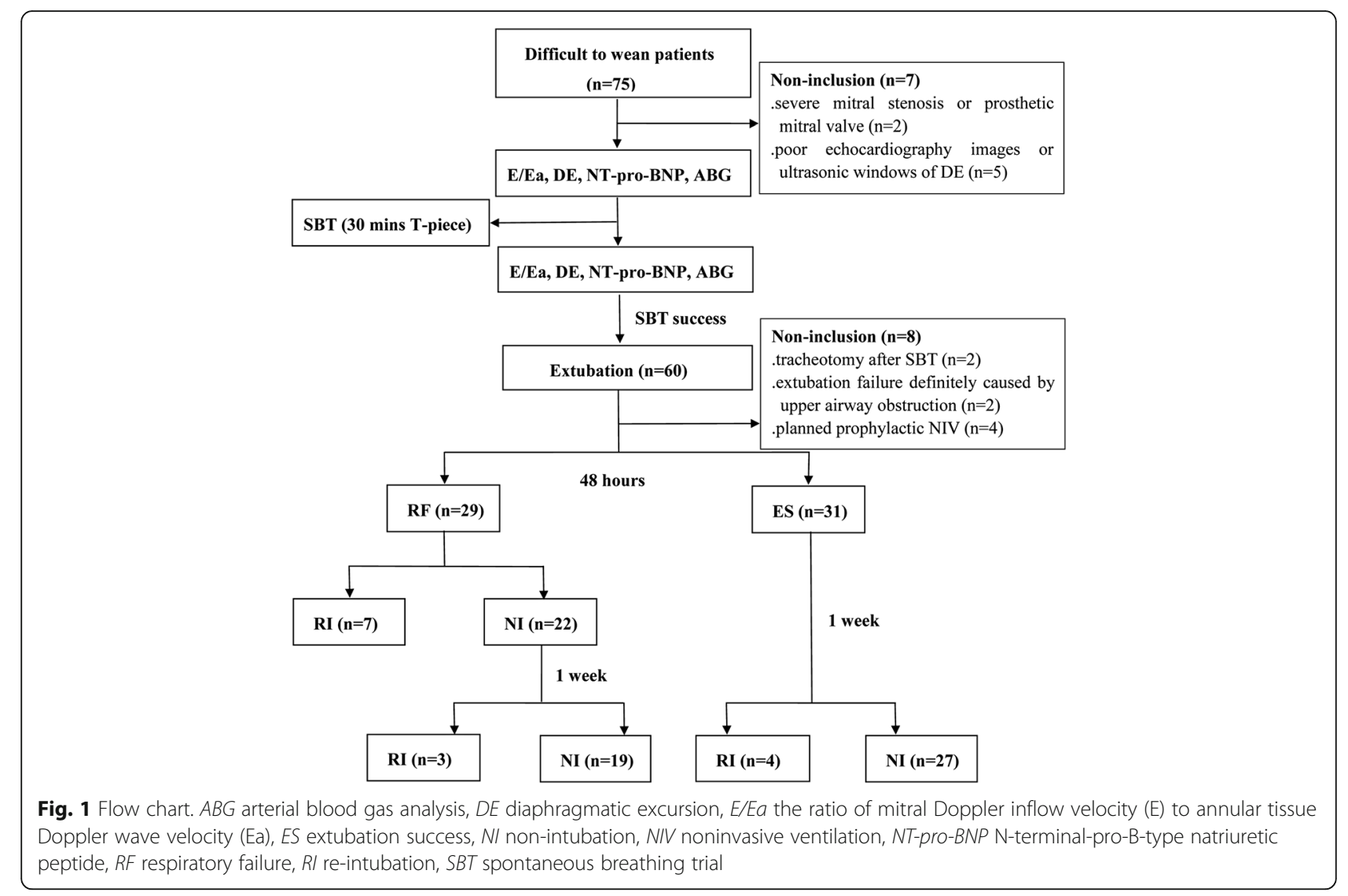

$\mathrm{E} / \mathrm{Ea}$ (average) after SBT was high in a patient in the RF subgroup (Fig. 4).

Meanwhile, NT-pro-BNP was analysed separately from the E/Ea and LVEF because of their significant correlations. Multivariate logistic regression analysis showed that the NT-pro-BNP level and $\mathrm{PaCO}_{2}$ after SBT, duration of the first intubation to extubation and haemoglobin were closely related to respiratory failure within $48 \mathrm{~h}$ (Additional file 1: Table S1). However, the OR value of NT-pro-BNP was very close to 1 .

\section{Predictor of re-intubation within 1 week in the respiratory} failure subgroup

Among all patients, 29 cases developed postextubation respiratory failure within $48 \mathrm{~h}$. These 29 cases received NIV, and 4 of them experienced re-intubation within 48 h. However, 6 of the remaining of 25 cases required re-intubation within 1 week. Of 10 cases with reintubation, 6 patients were re-intubated for heart failure and 4 patients for ineffective cough. One-way analysis of variance showed significant differences for $\mathrm{DE}$ (right) and DE (average) after SBT, the haemoglobin and BMI (Tables 4 and 5). However, multivariate logistic regression analysis showed that only DE (average) after SBT was associated with re-intubation within 1 week (OR 0.690 , CI $0.499-0.953, P=0.024$ ) (Table 6). The $P$ value for the Hosmer-Lemeshow test was 0.559. The AUC of DE (average) after SBT was 0.805 , and the cut-off value $\leq 12.6 \mathrm{~mm}$ showed the highest diagnostic accuracy with a sensitivity and specificity of $80 \%$ and $68.4 \%$, respectively (Fig. 5).

\section{Risk factors for re-intubation within 1 week in the extubation success subgroup}

Among 31 patients in the extubation success subgroup, 4 cases were re-intubated within 1 week after extubation ( 2 cases for abdominal infection, 1 case for ineffective cough and 1 case for heart failure). One-way analysis of variance showed significant differences for the duration from onset to the first intubation, $\mathrm{PH}$ after SBT, NTpro-BNP after SBT, and DE (average) before and after SBT (Tables 4 and 5). However, multivariate logistic regression analysis showed none of these factors were associated with re-intubation within 1 week (Additional file 1: Table S2).

\section{Discussion}

The most important findings in this study confirmed the different effects of cardiac and diaphragm function assessed by ultrasound on extubation outcomes in difficult-to-wean patients. Our results indicated that E/Ea (average) after SBT could predict respiratory failure within 
Table 1 Clinical characteristics

\begin{tabular}{|c|c|c|}
\hline \multirow[b]{2}{*}{ Variables } & \multicolumn{2}{|c|}{ Respiratory failure within $48 \mathrm{~h}$} \\
\hline & RF subgroup & ES subgroup \\
\hline $\mathrm{N}$ (cases) & 29 & 31 \\
\hline \multicolumn{3}{|l|}{ Demographic factors: } \\
\hline Age (yrs) & $70.8 \pm 15.6$ & $62.3 \pm 22.2$ \\
\hline Male & $18(62)$ & $17(55)$ \\
\hline $\mathrm{BMI}\left(\mathrm{kg} / \mathrm{m}^{2}\right)$ & $24.4 \pm 5.3$ & $24.3 \pm 4.3$ \\
\hline \multicolumn{3}{|l|}{ Comorbidities: } \\
\hline Chronic respiratory diseases $^{a}$ & $19(66)$ & $7(23)^{*}$ \\
\hline Coronary heart disease & $16(55)$ & $7(23)^{*}$ \\
\hline Myocardial infarction & $11(38)$ & $6(19)$ \\
\hline Hypertension & $17(59)$ & $19(61)$ \\
\hline Atrial fibrillation & $8(28)$ & $3(32)$ \\
\hline Diabetes & $11(38)$ & $12(39)$ \\
\hline Renal dysfunction & $10(29)$ & $5(16)$ \\
\hline Cerebral vascular diseases $^{\mathrm{b}}$ & $6(21)$ & $4(13)$ \\
\hline \multicolumn{3}{|l|}{ Clinical characteristics: } \\
\hline APACHE ॥ & $23.9 \pm 4.7$ & $20 \pm 6.4^{*}$ \\
\hline $\begin{array}{l}\text { Duration from onset to the first } \\
\text { intubation (d) }\end{array}$ & $6.3[1.5-9]$ & $3.6[1-6]^{*}$ \\
\hline $\begin{array}{l}\text { Duration of the first intubation } \\
\text { to extubation (d) }\end{array}$ & $10.4 \pm 6.9$ & $7.2 \pm 4.7^{*}$ \\
\hline RR (breaths/min) & $21.6 \pm 4.3$ & $21.5 \pm 4.7$ \\
\hline $\mathrm{V}_{\mathrm{T}}(\mathrm{l})$ & $0.43 \pm 0.12$ & $0.41 \pm 0.09$ \\
\hline $\mathrm{RSBI}$ & $55.8 \pm 22.2$ & $55.9 \pm 22.1$ \\
\hline GCS & $13.4[13-15]$ & $13.8[13-15]$ \\
\hline WBC $\left(\times 10^{9} / 1\right)$ & $9.8 \pm 3.9$ & $10.9 \pm 5.6$ \\
\hline Hemoglobin (g/l) & $103 \pm 23$ & $89 \pm 14^{*}$ \\
\hline Albumin (g/l) & $28.8 \pm 4.2$ & $27.7 \pm 3.9$ \\
\hline Plasma creatinine (micromole/l) & $121 \pm 74$ & $115 \pm 80$ \\
\hline
\end{tabular}

Data are presented as median $\pm \mathrm{SD}$ or median (IQR) or $\mathrm{n}(\%)$. APACHE // Acute Physiology and Chronic Health Evaluation II, BMI body mass index, ES extubation success, GCS Glasgow coma scale, $R F$ respiratory failure, $R R$ respiratory rate, $R S B I$ rapid shallow breathing index, $V_{T}$ tidal volume, $W B C$ white blood cell. ${ }^{a}$ Asthma, obsolete tuberculosis, chronic obstructive pulmonary disease, bronchiectasis and interstitial lung disease are included. ${ }^{\mathrm{b}} \mathrm{Cerebral}$ infarction, cerebral hemorrhage and subarachnoid hemorrhage are included. * Significant at $p<0.05$

$48 \mathrm{~h}$, and DE (average) after SBT might predict reintubation within 1 week in the respiratory failure subgroup. These results supported that cardiac diastolic function occurred in the short term after extubation, and diaphragm dysfunction persisted in the long term after extubation.

On the one hand, during abrupt transfer from mechanical ventilation to spontaneous breathing, decreases in intrathoracic pressures would augment venous return and intrathoracic blood volume, increasing the cardiac preload. Furthermore, increased left ventricular transmural pressures would augment cardiac afterload during the process. Otherwise, the increase in the breathing
Table 2 Laboratory and ultrasonic data before and after SBT

\begin{tabular}{|c|c|c|}
\hline \multirow[b]{2}{*}{ Variables } & \multicolumn{2}{|c|}{ Respiratory failure within $48 \mathrm{~h}$} \\
\hline & RF subgroup & ES subgroup \\
\hline $\mathrm{N}$ (cases) & 29 & 31 \\
\hline \multicolumn{3}{|l|}{ Before SBT } \\
\hline $\mathrm{PH}$ & $7.45 \pm 0.06$ & $7.46 \pm 0.05$ \\
\hline $\mathrm{PaCO}_{2}(\mathrm{mmHg})$ & $46.4 \pm 13$ & $39.1 \pm 5.1^{*}$ \\
\hline $\mathrm{PaO}_{2} / \mathrm{FiO}_{2}$ & $277 \pm 83$ & $281 \pm 80$ \\
\hline Lactic acid (mmol/l) & $1.2 \pm 0.6$ & $1.1 \pm 0.4$ \\
\hline NT-pro-BNP(pg/ml) & $6519 \pm 9162$ & $1578 \pm 1843^{*}$ \\
\hline Pleural effusion & $22(76)$ & $24(77)$ \\
\hline LVEF (\%) & $57 \pm 14$ & $64 \pm 9^{*}$ \\
\hline $\mathrm{E}(\mathrm{cm} / \mathrm{s})$ & $92.9 \pm 25.6$ & $78.2 \pm 18.4^{*}$ \\
\hline E/Ea (septal) & $18.2 \pm 8.1$ & $13 \pm 3.8^{*}$ \\
\hline E/Ea (lateral) & $12.8 \pm 5.1$ & $8.4 \pm 2.7^{\dagger}$ \\
\hline E/Ea (average) & $14.7 \pm 5.6$ & $10.1 \pm 2.8^{\dagger}$ \\
\hline DE (right) (mm) & $11.2 \pm 4.7$ & $10.1 \pm 4.7$ \\
\hline $\mathrm{DE}$ (left) (mm) & $11.6 \pm 6.3$ & $10.8 \pm 5.5$ \\
\hline $\mathrm{DE}$ (average) (mm) & $11.4 \pm 4.5$ & $10.5 \pm 3.4$ \\
\hline \multicolumn{3}{|l|}{ After SBT } \\
\hline $\mathrm{PH}$ & $7.43 \pm 0.05$ & $7.47 \pm 0.05^{*}$ \\
\hline $\mathrm{PaCO}_{2}(\mathrm{mmHg})$ & $48 \pm 11.7$ & $38.7 \pm 5.5^{\dagger}$ \\
\hline $\mathrm{PaO}_{2} / \mathrm{FiO}_{2}$ & $291 \pm 103$ & $275 \pm 79$ \\
\hline Lactic acid (mmol/l) & $1.1 \pm 0.5$ & $1.1 \pm 0.5$ \\
\hline NT-pro-BNP(pg/ml) & $6518[421-10,477]$ & $1471[176-1575]^{*}$ \\
\hline $\mathrm{E}(\mathrm{cm} / \mathrm{s})$ & $99.7 \pm 24.3$ & $85.1 \pm 18.2^{*}$ \\
\hline E/Ea (septal) & $18.6 \pm 6.5$ & $13.4 \pm 4.4^{*}$ \\
\hline E/Ea (lateral) & $14.4 \pm 7.3$ & $9.0 \pm 3.0^{*}$ \\
\hline E/Ea (average) & $15.8 \pm 6.2$ & $10.6 \pm 3.2^{\dagger}$ \\
\hline DE (right) (mm) & $13.7 \pm 6$ & $11 \pm 4.4$ \\
\hline DE (left) (mm) & $13.8 \pm 6.4$ & $13 \pm 5.4$ \\
\hline $\mathrm{DE}$ (average) (mm) & $13.7 \pm 5.4$ & $12 \pm 3.4$ \\
\hline
\end{tabular}

Data are presented as median \pm SD or median (IQR) or $n$ (\%). DE diaphragmatic excursion, $E$ mitral Doppler early peak diastolic velocity, $E / E a$ the ratio of mitral Doppler inflow velocity to annular tissue Doppler wave velocity, ES extubation success, LVEF left ventricular ejection fraction, NT-pro-BNP N-terminal-pro-B-type natriuretic peptide, $\mathrm{PaCO}_{2}$ arterial carbon dioxide tension, $\mathrm{PaO}_{2} / \mathrm{FiO}_{2}$ the ratio of arterial oxygen tension to fraction of inspired oxygen, $R F$ respiratory failure, $S B T$ spontaneous breathing trial. ${ }^{*}$ Significant at $p<0.05$, and ${ }^{\dagger}$ significant at $p<0.001$

work and discharge of catecholamine might increase the cardiac work and myocardial oxygen demand [18]. Therefore, cardiac diastolic function would become worse and could lead to postextubation respiratory failure quickly. On the other hand, diaphragm dysfunction usually occurred with chronic respiratory diseases or abdominal diseases, which were often accompanied with refractory respiratory failure or ineffective cough. These were two important reasons for re-intubation. Therefore, diaphragm dysfunction could be associated with re-intubation. Furthermore, other accessory respiratory muscles or NIV 


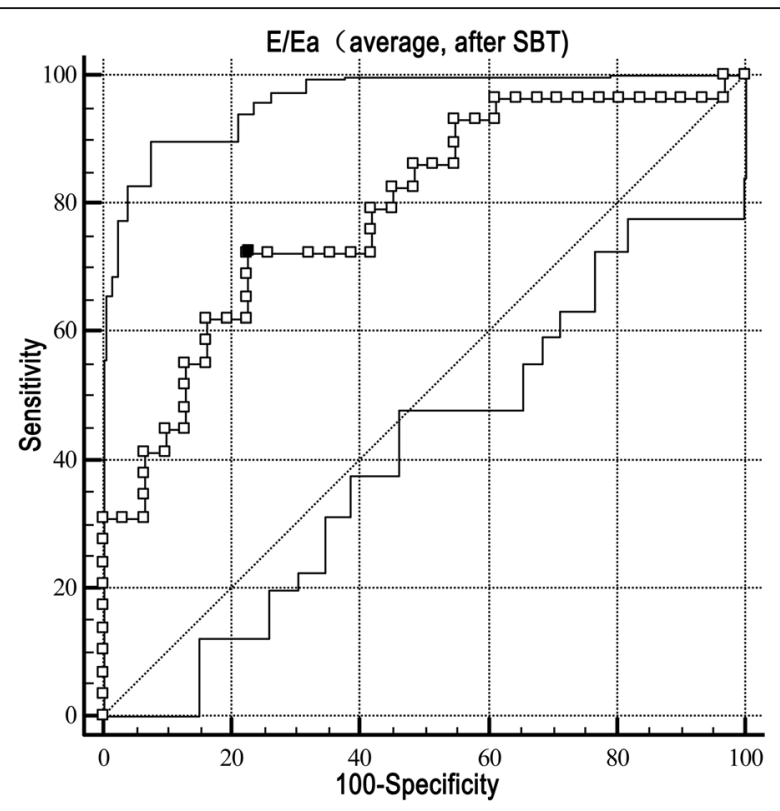

Fig. 2 The ROC curve for E/Ea (average) after SBT predicting respiratory failure within $48 \mathrm{~h}$. The AUC of E/Ea was $0.789(P<0.001)$ A cut-off value $\geq 12.5$ of E/Ea (average) after SBT showed the highest diagnostic accuracy with a sensitivity and specificity of 72.4 and $77.4 \%$, respectively. AUC area under curve, E/Ea the ratio of mitral Doppler inflow velocity (E) to annular tissue Doppler wave velocity (Ea), $R O C$ receiver operating characteristic curve, SBT spontaneous breathing trial

could partially compensate for diaphragm dysfunction. As a result, re-intubation often occurred in the long term, compared to postextubation respiratory failure.

In this study, we demonstrated that E/Ea (average) after SBT could predict respiratory failure within $48 \mathrm{~h}$, and that a cut-off value $\geq 12.5$ had the highest predictive value. These conclusions were partially in line with the results of early case studies [6-9]. However, three issues should be addressed. First, E/Ea (average) but not E/Ea (septal or lateral) after SBT was identified as an ideal predictor in this study; because 17 cases (28\%) were diagnosed with myocardial infarction in this study. E/Ea (average) instead of $\mathrm{E} / \mathrm{Ea}$ (septal or lateral) was recommended to reflect cardiac diastolic function in the presence of regional dysfunction by the Guidelines [19]. Second, the NT-pro-BNP level was higher in the respiratory failure subgroup, but further analysis showed that the OR value was very close to 1 , which limited its predictive value. As the NT-pro-BNP was easily affected by multiple factors, it might be more suitable for $\mathrm{E} / \mathrm{Ea}$ (average) to accurately reflect cardiac diastolic dysfunction related to extubation. Finally, there were no differences in DE between the respiratory failure and extubation success subgroups, indicating that diaphragm dysfunction did not play an important role in respiratory failure within $48 \mathrm{~h}$. Other accessary respiratory muscles could partially compensate for diaphragm dysfunction. Therefore, it often took a long time for diaphragm dysfunction to cause respiratory failure, compared to cardiac dysfunction. A study by Carrie et al. showed that DE could predict weaning failure with a low sensitivity and specificity of $59 \%$ and $71 \%$, respectively [20]. Weaning failure was defined as SBT failure, respiratory failure or death within $48 \mathrm{~h}$ after extubation. Although there were partial differences between the criteria for weaning failure and those for postextubation respiratory failure, DE seemed not to be significantly associated with respiratory failure within $48 \mathrm{~h}$.

In the respiratory failure subgroup, DE (average) after SBT was the only protective factor associated with reintubation within 1 week, which was a significant finding. The cut-off value $\leq 12.6 \mathrm{~mm}$ showed the highest diagnostic accuracy. As the diaphragm serves as a main part in the formation of the cough reflex arc, its function can partly reflect the ability to cough and discharge sputum. Many studies have indicated that cough strength is a good predictor of extubation failure [21-24]. Diaphragm dysfunction was closely related to ineffective cough and primary respiratory failure, which were considered two important reasons for re-intubation. Therefore, diaphragm dysfunction could help predict reintubation. Jiang JR et al. reported that the movements of the liver and spleen during SBT could predict extubation success within $72 \mathrm{~h}$, and that the cut-off value of $1.1 \mathrm{~cm}$ had the greatest sensitivity (84.4\%) and specificity (82.6\%) [10]. Kim WY et al. demonstrated that patients

Table 3 The parameters of the ROC curve of the predictors of respiratory failure within $48 \mathrm{~h}$

\begin{tabular}{llllllll}
\hline Variables & OR & $95 \% \mathrm{Cl}$ & P-value & Cut-off value & AUC & Sensitivity & Specificity \\
\hline Chronic respiratory diseases & 5.013 & $0.738-34.067$ & 0.099 & NA & NA & NA & NA \\
Duration from onset to the first intubation & 1.269 & $0.989-1.627$ & 0.061 & NA & NA & NA & NA \\
PH after SBT & $<0.001$ & $0-3.322$ & 0.066 & NA & NA & NA & NA \\
PaCO $_{2}$ after SBT & 1.146 & $0.980-1.340$ & 0.088 & NA & NA & NA & NA \\
LVEF & 0.904 & $0.833-0.981$ & 0.015 & $\leq 52$ & 0.646 & $34.5 \%$ & $96.8 \%$ \\
E/Ea (average) after SBT & 1.450 & $1.092-1.926$ & 0.010 & $\geq 12.5$ & 0.789 & $72.4 \%$ & $77.4 \%$ \\
\hline
\end{tabular}

AUC area under curve, $\mathrm{Cl}$ confidence interval, $E / E a$ the ratio of mitral Doppler inflow velocity to annular tissue Doppler wave velocity, $L V E F$ left ventricular ejection fraction, $N A$ not available, $\mathrm{PaCO}_{2}$ arterial carbon dioxide tension, $O R$ odds ratio, $R O C$ receiver operating characteristic curve, SBT spontaneous breathing trial 


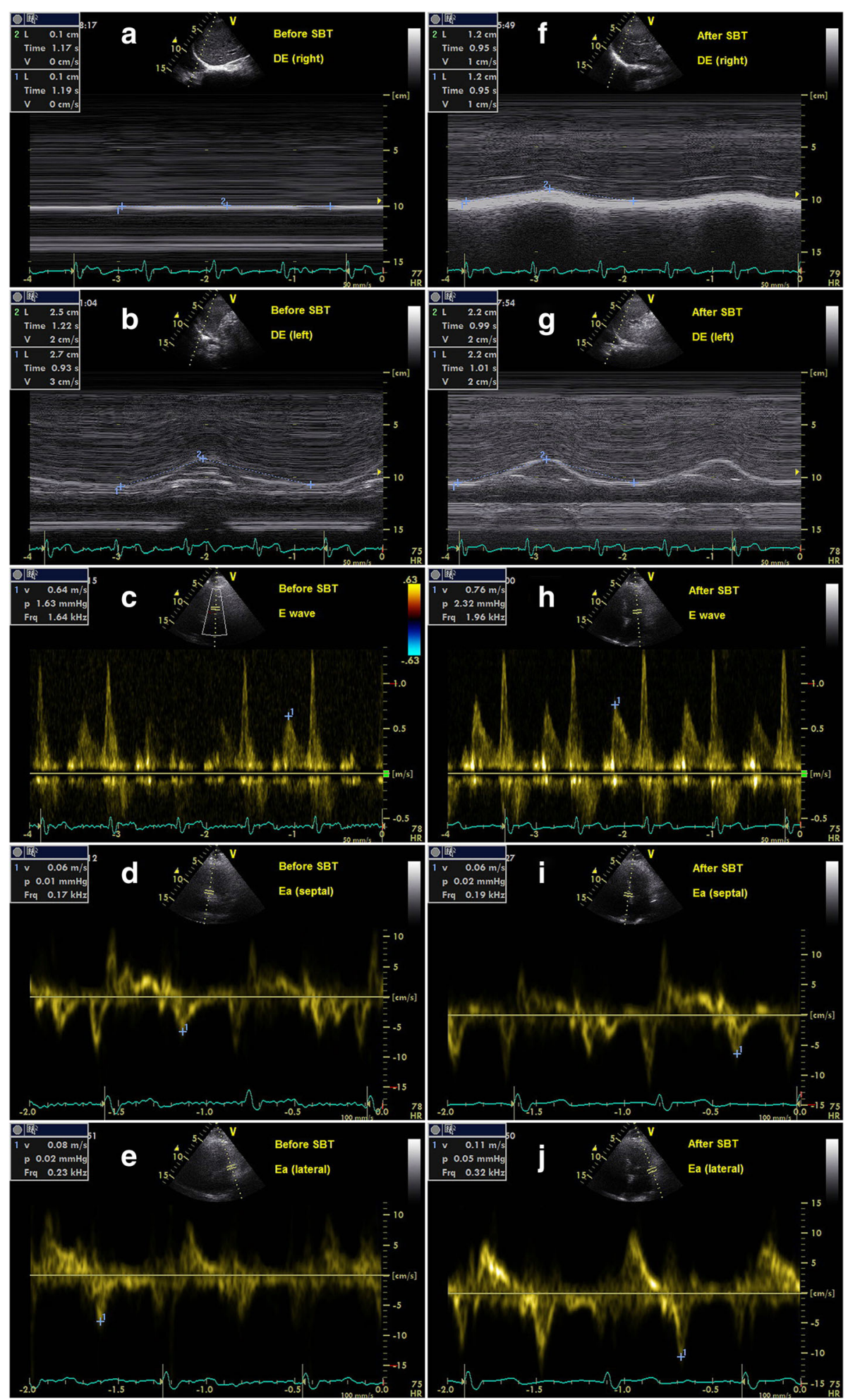

Fig. 3 The measurements of E/Ea and DE before and after SBT in a patient of extubation success. $\mathbf{a}, \mathbf{b}, \mathbf{c}, \mathbf{d}$, e represented the results before SBT, and $\mathbf{f}, \mathbf{g}, \mathbf{h}, \mathbf{i}, \mathbf{j}$ represented the results after SBT. a DE (right) was $1 \mathrm{~mm}$. b DE (left) was $26 \mathrm{~mm}$. c E was $64 \mathrm{~cm} / \mathrm{s}$. $\mathbf{d}$ Ea (septal) was $6 \mathrm{~cm} / \mathrm{s}$. e Ea (lateral) was $8 \mathrm{~cm} / \mathrm{s}$. f DE (right) was $12 \mathrm{~mm}$. g DE(left) was $22 \mathrm{~mm}$. h E was $76 \mathrm{~cm} / \mathrm{s}$. i Ea (septal) was $6 \mathrm{~cm} / \mathrm{s}$. j Ea (lateral) was $11 \mathrm{~cm} / \mathrm{s}$. Before SBT, DE (average) was $13.5 \mathrm{~mm}$, and E/Ea (average) was 9.1. After SBT, DE (average) was $17 \mathrm{~mm}$, and E/Ea (average) was 8.9. After extubation, the patient did not develop respiratory failure within $48 \mathrm{~h}$. The patient did not require re-intubation within 1 week. DE diaphragmatic excursion, E/Ea the ratio of mitral Doppler inflow velocity (E) to annular tissue Doppler wave velocity (Ea), SBT spontaneous breathing trial 


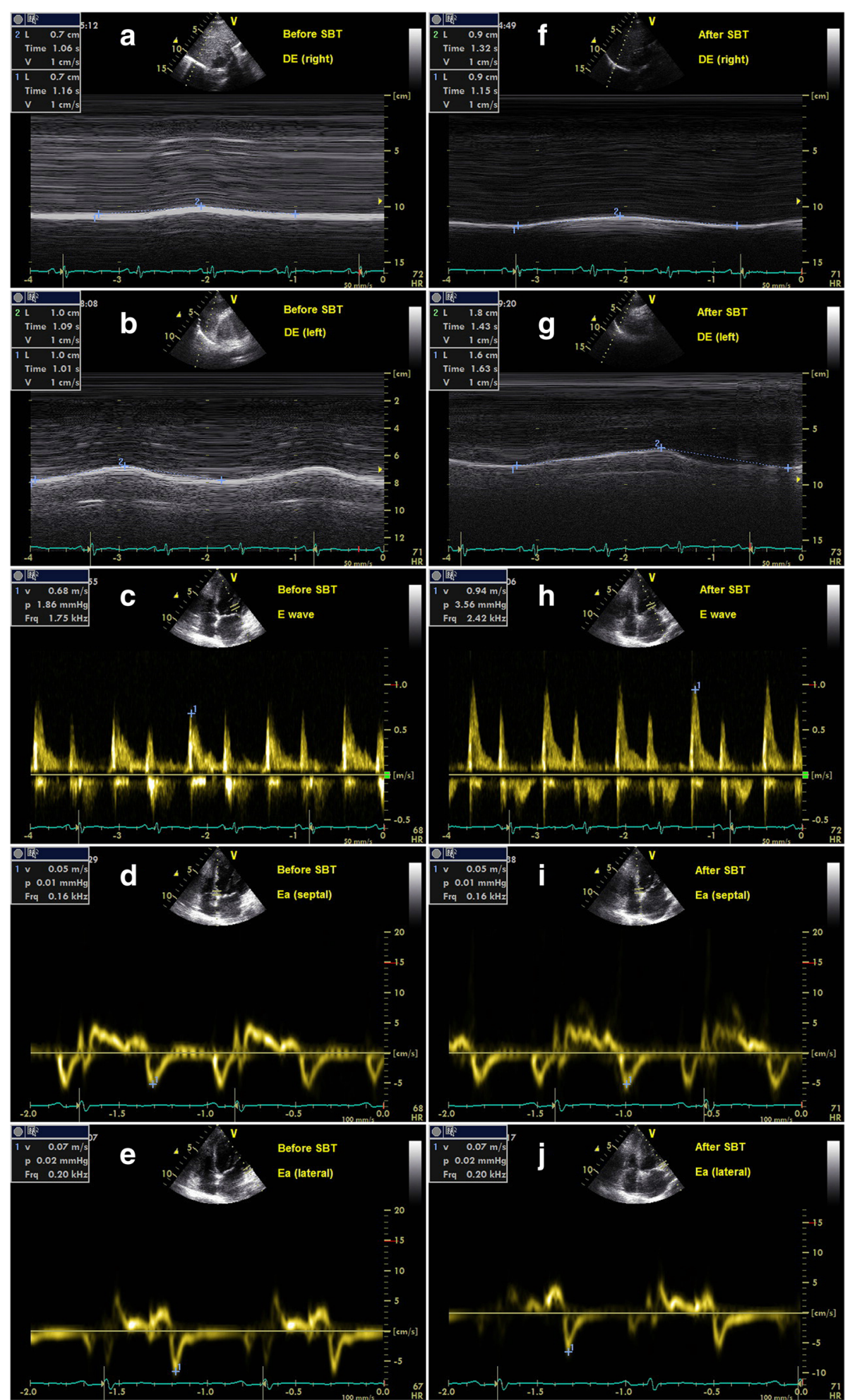

Fig. 4 (See legend on next page.) 
(See figure on previous page.)

Fig. 4 The measurements of E/Ea and DE before and after SBT in a patient of respiratory failure within $48 \mathrm{~h} . \mathbf{a}, \mathbf{b}, \mathbf{c}$, $\mathbf{d}$, e represented the results before SBT, and $\mathbf{f}, \mathbf{g}, \mathbf{h}, \mathbf{i}, \mathbf{j}$ represented the results after SBT. a DE (right) was $7 \mathrm{~mm}$. b DE (left) was $10 \mathrm{~mm}$. c E was $68 \mathrm{~cm} / \mathrm{s}$. d Ea (septal) was $5 \mathrm{~cm} / \mathrm{s}$. e Ea (lateral) was $7 \mathrm{~cm} / \mathrm{s}$. f DE (right) was $9 \mathrm{~mm}$. $\mathbf{g}$ DE (left) was $17 \mathrm{~mm}$. h E was $94 \mathrm{~cm} / \mathrm{s}$. i Ea (septal) was $5 \mathrm{~cm} / \mathrm{s}$. j Ea (lateral) was $7 \mathrm{~cm} / \mathrm{s}$. Before SBT, DE (average) was $8.5 \mathrm{~mm}$, and E/Ea (average) was 11.3. After SBT, DE (average) was $13 \mathrm{~mm}$, and E/Ea (average) was 15.7. After extubation, respiratory failure occurred within $48 \mathrm{~h}$ and then NIV was used. The patient was not re-intubated within 1 week and free of NIV in the end. DE diaphragmatic excursion, E/Ea the ratio of mitral Doppler inflow velocity (E) to annular tissue Doppler wave velocity (Ea), NIV noninvasive ventilation, SBT spontaneous breathing trial

with diaphragm dysfunction, defined as $\mathrm{DE}<10 \mathrm{~mm}$ or paradoxical movements during SBT, had higher rates of primary weaning failure and secondary weaning failure [11]. Our conclusions were partially consistent with these studies. However, three problems should be highlighted. First, DE (average) after SBT instead of DE (right) after SBT was identified as an ideal predictor in this study. In fact, the discrepancy of bilateral diaphragmatic movement was very common in this study, which was similar to another study mentioned above [11]. Unilateral diaphragm dysfunction could be compensated by the reverse side. Therefore, DE (average) could more accurately reflect the overall diaphragm function. Second, all patients received NIV in this subgroup, but 10 cases

Table 4 Clinical characteristics in the respiratory failure and extubation success subgroups

\begin{tabular}{|c|c|c|c|c|}
\hline \multirow[b]{2}{*}{ Variables } & \multicolumn{2}{|c|}{ Respiratory failure subgroup } & \multicolumn{2}{|c|}{ Extubation success subgroup } \\
\hline & Rl subgroup & $\mathrm{NI}$ subgroup & Rl subgroup & $\mathrm{Nl}$ subgroup \\
\hline $\mathrm{N}$ (cases) & 10 & 19 & 4 & 27 \\
\hline \multicolumn{5}{|l|}{ Demographic factors: } \\
\hline Age (yrs) & $70.1 \pm 21.5$ & $71.2 \pm 12.2$ & $70.0 \pm 11.5$ & $61.2 \pm 23.3$ \\
\hline Male & $6(60)$ & $12(63)$ & $4(100)$ & $13(48)$ \\
\hline BMI $\left(\mathrm{kg} / \mathrm{m}^{2}\right)$ & $21.6 \pm 4.1$ & $25.9 \pm 5.4^{*}$ & $23.9 \pm 1.1$ & $24.4 \pm 4.5$ \\
\hline \multicolumn{5}{|l|}{ Comorbidities: } \\
\hline Chronic respiratory diseases $^{\mathrm{a}}$ & $7(70)$ & $12(63)$ & $1(25)$ & $6(22)$ \\
\hline Coronary heart disease & $5(50)$ & $11(58)$ & $1(25)$ & $6(22)$ \\
\hline Myocardial infarction & $2(20)$ & $9(47)$ & $1(25)$ & $5(19)$ \\
\hline Hypertension & $5(50)$ & $12(63)$ & $3(75)$ & $16(59)$ \\
\hline Atrial fibrillation & $4(40)$ & $4(21)$ & $0(0)$ & $3(11)$ \\
\hline Diabetes & $2(20)$ & $6(32)$ & $2(50)$ & $8(30)$ \\
\hline Renal dysfunction & $6(60)$ & $5(26)$ & $3(75)$ & $9(33)$ \\
\hline Cerebral vascular diseases $^{\mathrm{b}}$ & $4(40)$ & $2(11)$ & $1(25)$ & $3(11)$ \\
\hline \multicolumn{5}{|l|}{ Clinical characteristics: } \\
\hline APACHE ॥ & $26.2 \pm 6.4$ & $22.7 \pm 3.0$ & $24.0 \pm 5.0$ & $19.3 \pm 6.4$ \\
\hline Duration from onset to the first intubation (d) & $9.0 \pm 7.0$ & $5.0 \pm 3.4$ & $1.0 \pm 0.8$ & $4.0 \pm 4.0^{*}$ \\
\hline Duration of the first intubation to extubation (d) & $13.6 \pm 9.6$ & $8.7 \pm 4.4$ & $5.8 \pm 3.0$ & $7.4 \pm 4.9$ \\
\hline RR (breaths/min) & $22.5 \pm 5.6$ & $21.2 \pm 3.5$ & $23 \pm 6.7$ & $21.3 \pm 4.4$ \\
\hline $\mathrm{V}_{\mathrm{T}}(\mathrm{I})$ & $0.40 \pm 0.12$ & $0.44 \pm 0.12$ & $0.38 \pm 0.09$ & $0.41 \pm 0.09$ \\
\hline RSBI & $63.9 \pm 33.1$ & $51.6 \pm 12.8$ & $63.9 \pm 29.0$ & $54.8 \pm 21.3$ \\
\hline GCS & $12.4 \pm 3.6$ & $14.0 \pm 1.0$ & $13.5[13-14]$ & $13.9[13-15]$ \\
\hline WBC $\left(\times 10^{9} / /\right)$ & $8.5 \pm 4.1$ & $10.6 \pm 3.6$ & $8.8 \pm 3.7$ & $11.3 \pm 5.8$ \\
\hline Hemoglobin (g/l) & $87.2 \pm 12.0$ & $111.5 \pm 23.3^{*}$ & $81.0 \pm 16.8$ & $90.6 \pm 14.0$ \\
\hline Albumin (g/l) & $28.9 \pm 5.1$ & $28.8 \pm 3.9$ & $25.3 \pm 3.3$ & $28.0 \pm 3.9$ \\
\hline Plasma creatinine (micromole/l) & $134.9 \pm 83.0$ & $113.0 \pm 70.7$ & $155.4 \pm 90.5$ & $109.4 \pm 79.0$ \\
\hline
\end{tabular}

Data are in median \pm SD or median (IQR) or $\mathrm{n}(\%)$. APACHE II Acute Physiology and Chronic Health Evaluation II, BMI body mass index, GCS Glasgow coma scale, $N I$ non-intubation, $R I$ re-intubation, $R R$ respiratory rate, $R S B I$ rapid shallow breathing index, $V_{T}$ tidal volume, $W B C$ white blood cell. ${ }^{a}$ Asthma, obsolete tuberculosis, chronic obstructive pulmonary disease, bronchiectasis and interstitial lung disease. ${ }^{\mathrm{b}}$ Cerebral infarction, cerebral hemorrhage and subarachnoid hemorrhage. ${ }^{*} p<0.05$ 
Table 5 Laboratory and ultrasonic data in the respiratory failure and extubation success subgroups before and after SBT

\begin{tabular}{|c|c|c|c|c|}
\hline \multirow[b]{2}{*}{ Variables } & \multicolumn{2}{|c|}{ Respiratory failure subgroup } & \multicolumn{2}{|c|}{ Extubation success subgroup } \\
\hline & Rl subgroup & $\mathrm{NI}$ subgroup & Rl subgroup & $\mathrm{Nl}$ subgroup \\
\hline N (cases) & 10 & 19 & 4 & 27 \\
\hline \multicolumn{5}{|l|}{ Before SBT } \\
\hline $\mathrm{PH}$ & $7.44 \pm 0.06$ & $7.46 \pm 0.06$ & $7.47 \pm 0.05$ & $7.46 \pm 0.05$ \\
\hline $\mathrm{PaCO}_{2}(\mathrm{mmHg})$ & $51.1 \pm 15.3$ & $44.2 \pm 11.6$ & $38.8 \pm 9.5$ & $39.1 \pm 4.4$ \\
\hline $\mathrm{PaO}_{2} / \mathrm{FiO}_{2}$ & $311 \pm 88$ & $261 \pm 77$ & $304 \pm 99$ & $278 \pm 78$ \\
\hline Lactic acid (mmol/l) & $1.2 \pm 0.6$ & $1.1 \pm 0.7$ & $1.1 \pm 0.8$ & $1.1 \pm 0.3$ \\
\hline NT-pro-BNP (pg/ml) & $8907 \pm 10,180$ & $5262 \pm 8597$ & $3043 \pm 2014$ & $1344 \pm 1744$ \\
\hline Pleural effusion & $7(70)$ & $15(79)$ & $4(100)$ & $20(74)$ \\
\hline LVEF (\%) & $58 \pm 16$ & $57 \pm 14$ & $58.5 \pm 7.9$ & $65.3 \pm 8.9$ \\
\hline$E(\mathrm{~cm} / \mathrm{s})$ & $97.0 \pm 24.6$ & $90.7 \pm 26.4$ & $82.1 \pm 28.6$ & $77.6 \pm 17.2$ \\
\hline E/Ea (septal) & $17.2 \pm 11.0$ & $18.7 \pm 6.4$ & $12.8 \pm 5.9$ & $13.0 \pm 3.6$ \\
\hline E/Ea (lateral) & $11.7 \pm 6.0$ & $13.4 \pm 4.6$ & $6.6 \pm 3.0$ & $8.7 \pm 2.6$ \\
\hline E/Ea (average) & $13.5 \pm 6.7$ & $15.4 \pm 5.1$ & $8.6 \pm 3.9$ & $10.3 \pm 2.6$ \\
\hline DE (right) (mm) & $9.6 \pm 4.4$ & $12.1 \pm 4.8$ & $6.0 \pm 1.4$ & $10.7 \pm 4.7$ \\
\hline $\mathrm{DE}$ (left) (mm) & $10.4 \pm 5.1$ & $12.3 \pm 6.9$ & $8.3 \pm 3.7$ & $11.2 \pm 5.6$ \\
\hline DE (average) (mm) & $10.0 \pm 3.4$ & $12.2 \pm 4.9$ & $7.2 \pm 2.3$ & $11.0 \pm 3.2^{*}$ \\
\hline \multicolumn{5}{|l|}{ After SBT } \\
\hline $\mathrm{PH}$ & $7.43 \pm 0.05$ & $7.44 \pm 0.06$ & $7.42 \pm 0.05$ & $7.47 \pm 0.04^{*}$ \\
\hline $\mathrm{PaCO}_{2}(\mathrm{mmHg})$ & $51.5 \pm 14.2$ & $46.1 \pm 10.1$ & $39.3 \pm 7.0$ & $38.6 \pm 5.4$ \\
\hline $\mathrm{PaO}_{2} / \mathrm{FiO}_{2}$ & $317 \pm 107$ & $278 \pm 101$ & $307 \pm 59$ & $271 \pm 81$ \\
\hline Lactic acid (mmol/l) & $1.1 \pm 0.5$ & $1.1 \pm 0.6$ & $1.5 \pm 1.0$ & $1.0 \pm 0.3$ \\
\hline NT-pro-BNP (pg/ml) & $8778 \pm 11,082$ & $5329 \pm 8654$ & $3631 \pm 3273$ & $1138 \pm 1517^{*}$ \\
\hline$E(\mathrm{~cm} / \mathrm{s})$ & $99.2 \pm 27.3$ & $99.9 \pm 23.3$ & $83.5 \pm 23.5$ & $85.3 \pm 17.8$ \\
\hline E/Ea (septal) & $17.8 \pm 7.8$ & $19.0 \pm 5.8$ & $12.6 \pm 5.3$ & $13.5 \pm 4.4$ \\
\hline E/Ea (lateral) & $13.2 \pm 8.0$ & $15.0 \pm 7.0$ & $7.2 \pm 2.5$ & $9.2 \pm 3.0$ \\
\hline E/Ea (average) & $14.6 \pm 7.0$ & $16.4 \pm 5.9$ & $9.1 \pm 3.4$ & $10.8 \pm 3.1$ \\
\hline DE (right) (mm) & $8.9 \pm 4.6$ & $16.2 \pm 5.1^{*}$ & $8.2 \pm 2.4$ & $11.5 \pm 4.5$ \\
\hline $\mathrm{DE}$ (left) (mm) & $10.7 \pm 5.3$ & $15.5 \pm 6.4$ & $9.6 \pm 2.4$ & $13.5 \pm 5.5$ \\
\hline DE (average) (mm) & $9.8 \pm 3.6$ & $15.8 \pm 5.1^{*}$ & $8.9 \pm 1.9$ & $12.5 \pm 3.4^{*}$ \\
\hline
\end{tabular}

Data are in median \pm SD or median (IQR) or $\mathrm{n}(\%)$. DE diaphragmatic excursion, $E$ mitral Doppler early peak diastolic velocity, E/Ea the ratio of mitral Doppler inflow velocity to annular tissue Doppler wave velocity, LVEF left ventricular ejection fraction, $N I$ non-intubation, NT-pro-BNP N-terminal-pro-B-type natriuretic peptide, $\mathrm{PaCO}_{2}$ arterial carbon dioxide tension, $\mathrm{PaO}_{2} / \mathrm{FiO}_{2}$ the ratio of arterial oxygen tension to fraction of inspired oxygen, $\mathrm{RI}$ re-intubation, $\mathrm{SBT}$ spontaneous breathing trial. ${ }^{*} p<0.05$

(34\%) required re-intubation within 1 week. Currently, NIV as an early weaning technique from mechanical ventilation is controversial [13]. NIV can be used to partially improve respiratory muscular fatigue and cardiac dysfunction, but it remains a challenge to correct ineffective cough. Diaphragm function can partially reflect the ability of cough. Therefore, diaphragm ultrasound could partially help identify patients with a high risk for re-intubation. Finally, Spadaro $S$ et al. demonstrated that the diaphragmatic-rapid shallow breathing index (DRSBI) could predict weaning failure with a high sensitivity of $94.1 \%$ and a specificity of $64.7 \%$, and the AUC was 0.89 [25]. D-RSBI was a good comprehensive index that could reflect both the diaphragm function and presence

Table 6 The parameters of the ROC curve of the predictor of re-intubation within 1 week in the respiratory failure subgroup

\begin{tabular}{llllllll}
\hline Variables & OR & $95 \% \mathrm{Cl}$ & $P$-value & Cut-off value & AUC & Sensitivity & Specificity \\
\hline DE (average) after SBT & 0.690 & $0.499-0.953$ & 0.024 & $\leq 12.6$ & 0.805 & $80 \%$ & $68.4 \%$ \\
\hline
\end{tabular}

AUC area under curve, $C l$ confidence interval, $D E$ diaphragmatic excursion, $O R$ odds ratio, $R O C$ receiver operating characteristic curve, $S B T$ spontaneous breathing trial 


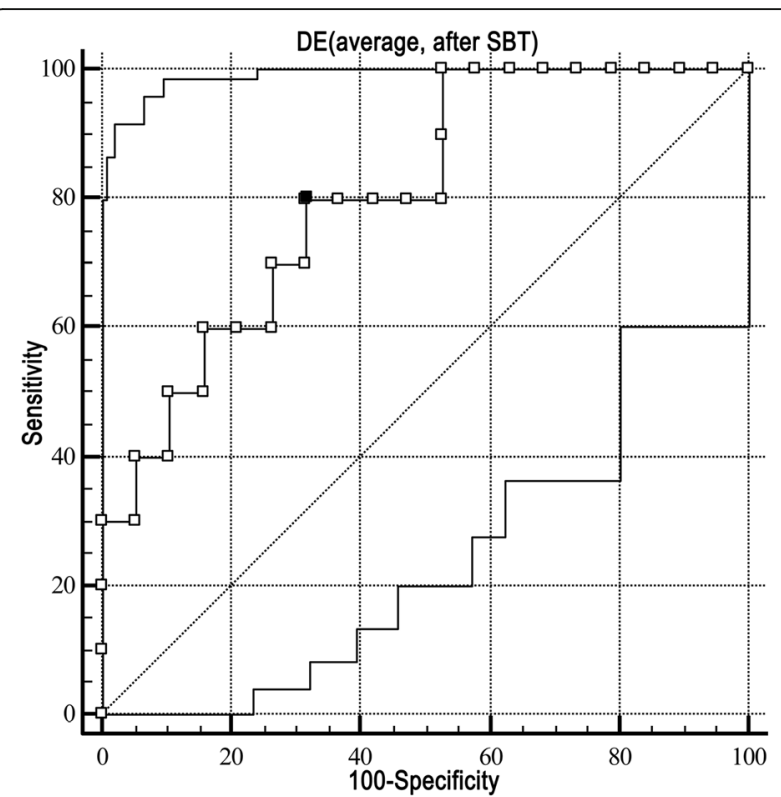

Fig. 5 The ROC curve for DE (average) after SBT predicting re-intubation within 1 week in the respiratory failure subgroup. The AUC of DE (average) after SBT was $0.805(P=0.008)$. A cut-off value $\leq 12.6 \mathrm{~mm}$ showed the highest diagnostic accuracy with a sensitivity and specificity of $80 \%$ and $68.4 \%$, respectively. AUC area under curve, DE diaphragmatic excursion, $R O C$ receiver operating characteristic curve, SBT spontaneous breathing trial

of rapid shallow breathing, a sign of overall imbalance between the mechanical load posed on the diaphragm and its ability to face the load. On the other hand, DRSBI could easily be affected by multiple factors such as the ability of the accessory respiratory muscles, the impaired diaphragmatic function, weaning-induced cardiac failure, excess mechanical load, and more. Therefore, DRSBI was a good predictor of weaning failure. However, we analysed the data of D-RSBI in this study and found that there were no significant differences between the reintubation and non-intubation subgroups (Additional file 1: Table S3). Compared to D-RSBI, DE was a simple and direct index reflecting diaphragm function. DE could partially reflect the severity of primary respiratory failure and ineffective cough, which were considered two important reasons for re-intubation. Therefore, DE could be a better predictor of re-intubation than D-RSBI.

Furthermore, one-way analysis of variance showed that DE (average) after SBT was a protective factor for reintubation within 1 week in the extubation success subgroup. However, further analysis showed that there were no correlations. These results could be explained by the small sample size and poorly balanced distribution in the re-intubation and non-intubation subgroups (4 and 27 cases).

In summary, the highlight of this study was that $\mathrm{E} / \mathrm{Ea}$ (average) after SBT could predict respiratory failure within $48 \mathrm{~h}$, and DE (average) after SBT might predict re-intubation within 1 week in the respiratory failure subgroup. This was an interesting phenomenon, which implied that cardiac diastolic dysfunction occurred quickly after extubation and could be partially improved by NIV and medication. On the other hand, diaphragm dysfunction often persisted in the long term after extubation. It was difficult to correct the dysfunction quickly even by NIV and medications.

It was noteworthy that severe diaphragm dysfunction could also lead to postextubation respiratory failure within $48 \mathrm{~h}$. In the study by Kim WY et al., DE medians were $7.0 \mathrm{~mm}$ and $7.9 \mathrm{~mm}$ in the right and left diaphragm in the diaphragmatic dysfunction group, respectively, which could explain a high incidence $(83 \%)$ of weaning failure within $48 \mathrm{~h}$ in this group [11]. Another study by Spadaro $S$ et al. showed that $\mathrm{DE}$ could predict weaning failure, with an AUC of 0.82 [25]. The average value of $\mathrm{DE}$ in the right diaphragm was $7.0 \mathrm{~mm}$ in the weaning failure group, which was remarkably lower than $13.7 \mathrm{~mm}$ in the respiratory failure subgroup in our study. Therefore, the lower the value of $\mathrm{DE}$, the earlier respiratory failure might occur after extubation. On the other hand, it is generally known that severe cardiac dysfunction can also cause re-intubation even by NIV and medication. Therefore, clinicians should analyse specific case features and assess the cardiac and diaphragm function together using bedside ultrasound in the weaning process.

\section{Study limitations}

This study has several limitations. First, different proportions of indications for intubation could have resulted in different conclusions. Therefore, it was helpful to analyse the results in different subgroups. However, 60 cases had a well-balanced distribution for the main reasons for intubation such as chronic respiratory diseases $(n=10)$, severe pneumonia $(n=19)$ and cardiac diseases $(n=15)$. Therefore, the predictive value of $\mathrm{E} / \mathrm{Ea}$ and $\mathrm{DE}$ can be evaluated in different diseases, such as chronic obstructive pulmonary disease or acute myocardial infarction, in the future. Second, the sample size in this study was small. Although DE (average) after SBT was one of protective factors for re-intubation within 1 week in the extubation success subgroup, further analysis showed that there were no correlations. Therefore, it is necessary to enroll sufficient patients to validate these conclusions in both respiratory failure and extubation success subgroups. Third, the percent change in the diaphragm thickness between end-expiration and end-inspiration was identified as a good predictor of extubation success $[12,26,27]$. However, we did not take this indicator into consideration at the beginning in this study. We are planning on adding the percent change in diaphragm thickness to analysis in our next study. Fourth, neither 
E/Ea nor DE can reflect other aetiologies, such as excess secretions, upper airway obstruction, mental status, etc. Therefore, extubation outcomes should continue to be based on specific case features. Finally, the GCS score, instead of the Richmond Agitation and Sedation Scale (RASS) score, was used to evaluate the level of sedation before SBT. The RASS score is more accurate and appropriate than the GCS score. Although there are no significant differences in the GCS score between different subgroups in this study, it is necessary for the RASS score to be used to assess the effect of extubation outcomes in a future study.

\section{Conclusions}

E/Ea (average) after SBT could help predict respiratory failure within $48 \mathrm{~h}$ after extubation. However, DE (average) after SBT could help predict re-intubation within 1 week in the respiratory failure subgroup. TTE and diaphragm ultrasound should be performed in different diseases to confirm these conclusions.

\section{Additional file}

Additional file 1: The criteria for readiness to wean and SBT and NIV, and the detailed methods for measuring E/Ea and LVEF. Table S1. The parameters of the predictors of respiratory failure within $48 \mathrm{~h}$ including NT-pro-BNP (after SBT). Table S2. The parameters of the predictors of re-intubation within 1 week in the extubation success subgroup. Table S3. The D-RSBI in the re-intubation and non-intubation subgroups. (DOC $67 \mathrm{~kb}$ )

\section{Abbreviations \\ APACHE: Acute physiology and chronic health evaluation; AUC: Area under curve; BNP: B-type natriuretic peptide; Cl: Confidence interval; DE: Diaphragmatic excursion; D-RSBI: Diaphragmatic-rapid shallow breathing index; E/A: The ratio of mitral Doppler early peak diastolic velocity to late peak diastolic velocity; E/ Ea: The ratio of mitral Doppler inflow velocity (E) to annular tissue Doppler wave velocity (Ea); ES subgroup: Extubation success subgroup; $\mathrm{FiO}_{2}$ : Proper fraction of inspired oxygen; GCS: Glasgow coma scale; ICU: Intensive care units; LVEF: Left ventricular ejection fraction; NI subgroup: Non-intubation subgroup; NIV: Noninvasive ventilation; NT-pro-BNP: N-terminal-pro-BNP; OR: Odds ratio; $\mathrm{PaCO}_{2}$ : Arterial carbon dioxide tension; $\mathrm{PaO}_{2}$ : Arterial oxygen tension; RASS: Richmond agitation and sedation scale; RF subgroup: Respiratory failure subgroup; RI subgroup: Re-intubation subgroup; ROC: Receiver operating characteristic; RR: Respiratory rate; RSBI: Rapid shallow breathing index; SBT: Spontaneous breathing trial; $\mathrm{SpO}_{2}$ : Percutaneous oxygen saturation; TTE: Transthoracic echocardiography; $\bigvee_{T}$ : Tidal volume}

\section{Acknowledgments}

The authors thank the medical and nursing staff of 4 ICU centers (RICU, SICU, CCU and EICU) and department of Ultrasound of Beijing Chaoyang Hospital for their valuable cooperation in this study. Appreciation also goes to the medical staff of the Department of Respiratory and Critical Care Medicine of Beijing Jishuitan Hospital.

\section{Funding}

This study was supported by Beijing Municipal Administration of Hospitals Clinical Medicine Development of Special Funding Support (No.ZYLX201312), in part by a grant from Beijing High-Grade Talents Health Technology Fund (No.2011-2-06) and Capital Health Research and Development of Special Funding Support (No.2016-1-1061).

\section{Availability of data and materials}

The original data in the current study can be available from the corresponding author on reasonable request.

\section{Authors' contributions}

ZHT performed study design and conception, study supervision, funding-raising, and administration. $L L$ drafted and revised the manuscript, performed study design and literature research. YDL performed technical operation and technical support. XKC performed study design and conception, data interpretation and revision of manuscript. YWL performed the statistical analysis and data collection. BS, WXL, WG, SW, SZ, MLC, JGX, FS, XM, HZS carried out data collection and data analysis. All authors read and approved the final manuscript.

\section{Ethics approval and consent to participate}

The study was approved by an Institutional Review Board of Beijing Chaoyang Hospital on Sep 24th, 2012. (No.2012-ke-88). The written informed consents were obtained from the patients' immediate family members.

\section{Consent for publication}

Not applicable.

\section{Competing interests}

The authors declare that they have no competing interests.

\section{Publisher's Note}

Springer Nature remains neutral with regard to jurisdictional claims in published maps and institutional affiliations.

\section{Author details}

${ }^{1}$ Department of Respiratory and Critical Care Medicine, Beijing Institute of Respiratory Medicine, Beijing Chaoyang Hospital, Capital Medical University, NO. 8 Gongren Tiyuchang Nanlu, Chaoyang District, Beijing 100020, China. ${ }^{2}$ Department of Respiratory and Critical Care Medicine, Beijing Jishuitan Hospital, NO. 31 Xinjiekou East District, Beijing 100035, China. ${ }^{3}$ Department of Ultrasound, Beijing Chaoyang Hospital, Capital Medical University, NO. 8 Gongren Tiyuchang Nanlu, Chaoyang District, Beijing 100020, China. ${ }^{4}$ Department of Surgery Intensive Care Unit, Beijing Chaoyang Hospital, Capital Medical University, NO. 8 Gongren Tiyuchang Nanlu, Chaoyang District, Beijing 100020, China. ${ }^{5}$ Department of Emergency Medicine, Beijing Chaoyang Hospital, Capital Medical University, NO. 8 Gongren Tiyuchang Nanlu, Chaoyang District, Beijing 100020, China. ${ }^{6}$ Department of Clinical Epidemiology Research Center, Beijing Jishuitan Hospital, NO. 31 Xinjiekou East District, Beijing 100035, China. ${ }^{7}$ Department of Cardiology, Beijing Chaoyang Hospital, Capital Medical University, NO. 8 Gongren Tiyuchang Nanlu, Chaoyang District, Beijing 100020, China. ${ }^{8}$ Department of Intensive care medicine, China-Japan Friendship Hospital, No.2 Yinghua East Street, Beijing 100029, China.

Received: 23 February 2017 Accepted: 15 November 2017

Published online: 01 December 2017

References

1. Boles JM, Bion J, Connors A, Herridge M, Marsh B, Melot C, Pearl R, Silverman H, Stanchina M, Vieillard-Baron A, et al. Weaning from mechanical ventilation. Eur Respir J. 2007;29(5):1033-56.

2. Thille AW, Richard JC, Brochard L. The decision to extubate in the intensive care unit. Am J Respir Crit Care Med. 2013;187(12):1294-302.

3. Chien JY, Lin MS, Huang YC, Chien YF, Yu CJ, Yang PC. Changes in B-type natriuretic peptide improve weaning outcome predicted by spontaneous breathing trial. Crit Care Med. 2008;36(5):1421-6.

4. Mekontso-Dessap A, de Prost N, Girou E, Braconnier F, Lemaire F, Brun-Buisson C, Brochard L. B-type natriuretic peptide and weaning from mechanical ventilation. Intensive Care Med. 2006:32(10):1529-36.

5. Grasso S, Leone A, De Michele M, Anaclerio R, Cafarelli A, Ancona G, Stripoli T, Bruno F, Pugliese P, Dambrosio M, et al. Use of N-terminal pro-brain natriuretic peptide to detect acute cardiac dysfunction during weaning failure in difficult-to-wean patients with chronic obstructive pulmonary disease. Crit Care Med. 2007;35(1):96-105.

6. Lamia B, Maizel J, Ochagavia A, Chemla D, Osman D, Richard C, Teboul IL. Echocardiographic diagnosis of pulmonary artery occlusion pressure 
elevation during weaning from mechanical ventilation. Crit Care Med. 2009;37(5):1696-701.

7. Caille V, Amiel JB, Charron C, Belliard G, Vieillard-Baron A, Vignon P. Echocardiography: a help in the weaning process. Crit Care. 2010;14(3):R120

8. Papanikolaou J, Makris D, Saranteas T, Karakitsos D, Zintzaras E, Karabinis A, Kostopanagiotou G, Zakynthinos E. New insights into weaning from mechanical ventilation: left ventricular diastolic dysfunction is a key player. Intensive Care Med. 2011;37(12):1976-85.

9. Moschietto S, Doyen D, Grech L, Dellamonica J, Hyvernat H, Bernardin G. Transthoracic echocardiography with Doppler tissue imaging predicts weaning failure from mechanical ventilation: evolution of the left ventricle relaxation rate during a spontaneous breathing trial is the key factor in weaning outcome. Crit Care. 2012;16(3):R81.

10. Jiang JR, Tsai TH, Jerng JS, Yu CJ, Wu HD, Yang PC. Ultrasonographic evaluation of liver/spleen movements and extubation outcome. Chest. 2004;126(1):179-85.

11. Kim WY, Suh HJ, Hong SB, Koh Y, Lim CM. Diaphragm dysfunction assessed by ultrasonography: influence on weaning from mechanical ventilation. Crit Care Med. 2011;39(12):2627-30

12. Farghaly S, Hasan AA. Diaphragm ultrasound as a new method to predict extubation outcome in mechanically ventilated patients. Aust Crit Care. 2017;30(1):37-43.

13. Girault C, Bubenheim M, Abroug F, Diehl JL, Elatrous S, Beuret P, Richecoeur J, L'Her E, Hilbert G, Capellier G, et al. Noninvasive ventilation and weaning in patients with chronic hypercapnic respiratory failure: a randomized multicenter trial. Am J Respir Crit Care Med. 2011;184(6):672-9.

14. Matamis D, Soilemezi E, Tsagourias M, Akoumianaki E, Dimassi S, Boroli F, Richard JC, Brochard L. Sonographic evaluation of the diaphragm in critically ill patients. Technique and clinical applications. Intensive Care Med. 2013;39(5):801-10

15. Keenan SP, Powers C, McCormack DG, Block G. Noninvasive positive-pressure ventilation for postextubation respiratory distress: a randomized controlled trial. JAMA. 2002;287(24):3238-44.

16. Esteban A, Frutos-Vivar F, Ferguson ND, Arabi Y, Apezteguia C, Gonzalez M, Epstein SK, Hill NS, Nava S, Soares MA, et al. Noninvasive positive-pressure ventilation for respiratory failure after extubation. $N$ Engl J Med. 2004;350(24):2452-60.

17. Ferrer M, Valencia M, Nicolas JM, Bernadich O, Badia JR, Torres A. Early noninvasive ventilation averts extubation failure in patients at risk: a randomized trial. Am J Respir Crit Care Med. 2006;173(2):164-70

18. Teboul JL, Monnet X, Richard C. Weaning failure of cardiac origin: recent advances. Crit Care. 2010;14(2):211.

19. Nagueh SF, Appleton CP, Gillebert TC, Marino PN, Oh JK, Smiseth OA, Waggoner AD, Flachskampf FA, Pellikka PA, Evangelista A.

Recommendations for the evaluation of left ventricular diastolic function by echocardiography. J Am Soc Echocardiogr. 2009;22(2):107-33.

20. Carrie C, Gisbert-Mora C, Bonnardel E, Gauche B, Biais M, Vargas F, Hilbert G. Ultrasonographic diaphragmatic excursion is inaccurate and not better than the MRC score for predicting weaning-failure in mechanically ventilated patients. Anaesth Crit Care Pain Med. 2017;36(1):9-14.

21. Khamiees M, Raju P, DeGirolamo A, Amoateng-Adjepong Y, Manthous CA. Predictors of extubation outcome in patients who have successfully completed a spontaneous breathing trial. Chest. 2001:120(4):1262-70.

22. Smina M, Salam A, Khamiees M, Gada P, Amoateng-Adjepong Y, Manthous CA. Cough peak flows and extubation outcomes. Chest. 2003;124(1):262-8.

23. Salam A, Tilluckdharry L, Amoateng-Adjepong Y, Manthous CA. Neurologic status, cough, secretions and extubation outcomes. Intensive Care Med. 2004;30(7):1334-9.

24. Su WL, Chen YH, Chen CW, Yang SH, Su CL, Perng WC, Wu CP, Chen JH. Involuntary cough strength and extubation outcomes for patients in an ICU. Chest. 2010;137(4):777-82.

25. Spadaro S, Grasso S, Mauri T, Dalla Corte F, Alvisi V, Ragazzi R, Cricca V Biondi G, Di Mussi R, Marangoni E, et al. Can diaphragmatic ultrasonography performed during the T-tube trial predict weaning failure? The role of diaphragmatic rapid shallow breathing index. Crit Care. 2016;20(1):305.

26. DiNino E, Gartman EJ, Sethi JM, McCool FD. Diaphragm ultrasound as a predictor of successful extubation from mechanical ventilation. Thorax. 2014;69(5):423-7.

27. Ferrari G, De Filippi G, Elia F, Panero F, Volpicelli G, Apra F. Diaphragm ultrasound as a new index of discontinuation from mechanical ventilation. Crit Ultrasound J. 2014;6(1):8.

\section{Submit your next manuscript to BioMed Central and we will help you at every step:}

- We accept pre-submission inquiries

- Our selector tool helps you to find the most relevant journal

- We provide round the clock customer support

- Convenient online submission

- Thorough peer review

- Inclusion in PubMed and all major indexing services

- Maximum visibility for your research

Submit your manuscript at www.biomedcentral.com/submit
Biomed Central 